\title{
Environmental Regulation, Industrial Heterogeneity and Value Compensation
}

\author{
Lisha Chen ${ }^{1,2,}{ }^{*}$,and Changqing Ding ${ }^{1}$ \\ ${ }^{1}$ Business School of Hohai University, Nanjing 211100, China \\ ${ }^{2}$ School of Business Administration of Nanjing Audit University, Nanjing 211815, China \\ Corresponding Email: chenlisha006@163.com
}

\begin{abstract}
This article divided environmental regulation tools into market-oriented environmental regulation, environmental administrative control and environmental pollution regulation, divided enterprises into pollution intensive and clean production enterprises. Take Chinese manufacturing listed companies as research object, through panel data analysis, this article measured short-term and long-term value compensation effect and the possible existence of the threshold effect and cumulative effect of different environmental regulation tools for different types of micro enterprises to inspect Porter hypothesis and to inspect the effect of Chinese environmental regulation.
\end{abstract}

Keywords. Environmental regulation, heterogeneity, value compensation.

\section{Introduction}

Deterioration of living environment forced governments to take more efforts on environmental regulation. Under the pressure of environmental regulation, the corresponding coping behavior would be taken by enterprises to reduce the impact of environmental regulation. The coping behaviors may be end-of-pipe control, technology innovation, change of operation direction, etc. All the coping behavior world undoubtedly lead to energy conservation and emissions reduction, and will eventually be reflected in the enterprise value changes. So it is ponderable to link environmental regulation and enterprise value to search the influence of environmental regulation on enterprise, to observe whether value compensation effect do exist, and whether industry heterogeneity affect the influence.

\section{Literature review and research hypothesis}

\subsection{The influence of environmental regulation on corporate value}

Economics essence of environmental regulation is internalization of negative externalities of environmental pollution as enterprise's cost. To achieve more profits, micro enterprises, inevitably faced with the tradeoffs between cost and enterprise performance. To solve this problem, different enterprises make different decisions. From strategic perspective, enterprises would choose different environment strategic and make different environmental management decisions. From investment perspective, on the one hand, environmental regulation can make the enterprise to strengthen technology research to improve energy efficiency and reduce energy consumption and pollution, on the other, environmental regulation may force companies to invest in other areas to avoid environmental regulation to reduce business risk. No matter what kinds of decisions are made, the goal of rational corporate is to improve competitiveness and finally increase the enterprise value.

Hypothesis 1a: environmental regulation affects enterprise value.

Enterprise value includes short-term and long-term value. The impact of technological innovation on enterprise value has cumulative effect and threshold effect. Technology innovation present as corporate spending in short term, that is why the feedback of enterprise technology given raised by environmental regulation to enterprise value of the short-term performance is negative or of no significant role. In the long run, green innovation accumulation bring about promotion of product image, as well as the green innovation especially the predictive green innovation can bring about reformation of products structure and industry structure which will infuse new competitive advantage into enterprises. Therefore, there is a positive relation between environmental regulation and the enterprise long-term value. 
Hypothesis $1 \mathrm{~b}$ : the relationship between environmental regulation and short-term enterprise value is negative or of no significant role.

Hypothesis 1c: there is a positive relation between environmental regulation and enterprise long-term value

\subsection{The influence of different environmental regulation to the enterprise value is different}

Environmental regulation is a complex policy tool system. Different types of environmental regulation have different operation mechanisms. And the influence mechanism on enterprise strategy formulation and implementation so as to influence value-added effect must be different. According to Ling Li and Feng Tao (2012) [1] this paper divided environmental regulation into administrative-controlling environmental regulation and market-oriented environmental regulation.

Administrative-controlling environmental regulation mainly includes emission standards, product technical standard and penalty which can be divided into two parts of legislation (environmental administrative control) and law enforcement (environmental pollution regulation). Environmental administrative control is to directly affect the choice of the polluters to make beneficial to environmental protection by laws, regulations, policies and systems legislated. So it is a kind of beforehand supervision, which can give clear direction to enterprise to establish long-term friendly environment strategies. Environmental pollution control is a kind of after-event supervision. When companies choose to discharge illegally, they need play game with government. When government improve the pollution control, the likelihood of be punished for illegal discharge is increased, which would encourage enterprises to select technology investments or change direction of enterprise management for less pollution as much as possible. Therefore the latter influences short-term decisions of enterprises, and can't guide enterprises to take the initiative to establish friendly environmental strategy. Market-oriented environmental regulation mainly includes the pollution tax, tax deduction, the clean development mechanism (CDMs). The primary of market-oriented environmental regulation tools in China is emission charges [2]. Emission charges increase the cost of enterprises and reduce their profits, but the technical level is a significant variable to adjust the function of enterprise cost and the profit. Market-oriented environmental regulation can give companies a clear direction of cleaner production and encourage enterprises to pursuit long-term strategy.

Hypothesis 2: different types of environmental regulation have different effects on corporate value.

\subsection{The industry heterogeneity in the impact of environmental regulation on enterprise value}

From degree of contamination enterprises can be divided into pollution intensive enterprise and clean productionoriented enterprises. The influence of environmental regulation on the two types of enterprises is different. The higher level of pollution enterprises do, the more environmental regulation would impose on them, and environmental compliance costs are relatively higher. On the one hand, there are more hinders for enterprises to invest technology innovation, on the other hand, only by investing more in technology to improve efficiency pollution intensive enterprises can make up for the high environmental costs. Thus it can effectively motivate pollution intensive enterprise to take technical innovation. And for the industry of low level of pollution, effect of environmental regulation on industry production action is not obvious, so the influence of environmental regulation on its production and operation is not obvious.

Hypothesis 3: Impact of Environmental regulation on enterprise value exist industry heterogeneity.

\section{Empirical design}

\subsection{Variable definitions and data sources}

Dependent variables: enterprise value (V) was divided into short-term and long-term value. The short-term value measured in this article is based on accounting indicators, using return on assets (ROA) to illustrate; long-term value is the expected value of the enterprise, use enterprise Tobin's q value to illustrate which represent the ratio of the enterprise's market value and replacement cost.

Independent variables: Environmental regulation variable was divided into market-oriented environmental regulation (PEG), environmental administrative control (GOV) and environmental pollution regulation (CAS). Refer to the practice of Shu Li and WeiGuo Weng(2014) [3],GOV were expressed by the number of regional administrative rules and regulations promulgated; CAS in various areas was measured by environmental administrative penalty cases accepted; PEG was measured by the ratio of regional emission charges and the gross industrial output value.

Control variables: control variables in this paper includes property rights attributes (State), Industry (Industry), the joining together of two position (Dual), company size (Size), share ratio of the largest shareholder (First), equity Balance degree (i.e., the second - fifth big shareholder's stake, Balance), the proportion of management shareholding (Manager), financial leverage (Lev), enterprise Growth ability (Growth), Age (Age).

Sample selection and data sources: Because this article is mainly to investigate the influence of environmental regulation on industrial enterprises, so agriculture, mining, and all companies in service industries were eliminated from the samples. Companies of ST, PT, SST * and those missing variable samples were also eliminated. Given the 
availability of raw data of relevant indexes, the study period this paper chose is 2001-2013.Among them, the number of regional administrative rules and regulations promulgated and the data of emission charges are from China's Environmental Yearbook; Enterprise asset data are from CSMAR database, annual reports of listed companies and other kinds of data are calculated from China Statistical Yearbook.

\subsection{Research methods and models}

To validate compensation effect of environmental regulation on value of industrial enterprises, regression models were built as follows:

$$
\begin{aligned}
& \text { ROA }=\alpha_{0}+\beta_{1} X+\beta_{2} \text { State }+\beta_{3} \text { Industry }+\beta_{4} \text { Dual }+\beta_{5} \text { Size }+\beta_{6} \text { First }+\beta_{7} \text { Balance }+ \\
& \beta_{8} \text { Manager }+\beta_{9} \text { Lev }+\beta_{10} \text { Growth }+\beta_{11} \text { Age }+\varepsilon
\end{aligned}
$$

$$
\begin{aligned}
& \text { TobinQ }=\alpha_{0}+\beta_{1} \mathrm{X}+\beta_{2} \text { State }+\beta_{3} \text { Industry }+\beta_{4} \text { Dual }+\beta_{5} \text { Size }+\beta_{6} \text { First }+\beta_{7} \text { Balance }+ \\
& \beta_{8} \text { Manager }+\beta_{9} \text { Lev }+\beta_{10} \text { Growth }+\beta_{11} \text { Age }+\varepsilon
\end{aligned}
$$

In model (1), (2), X represents the intensity of GOV, CAS and PEG.

\section{Empirical analysis and results discussion}

Due to the hysteresis, we designed the environmental regulation variable lag one period when we do the statistical analysis to inspect the effect of different environmental regulation tools on both short-term and long-term value of listed companies.

\begin{tabular}{|c|c|c|c|c|c|c|}
\hline Variable & \multicolumn{3}{|c|}{ ROA } & \multicolumn{3}{|c|}{ Tobin $\mathrm{Q}$} \\
\hline \multirow[t]{2}{*}{ Old } & $0.00260^{* * *}$ & $0.00364^{* *}$ & $0.00320^{* * *}$ & $0.0860^{* * *}$ & $0.0967^{* * *}$ & $0.0923^{* * * *}$ \\
\hline & $(4.89)$ & (7.67) & $(6.85)$ & $(8.98)$ & $(11.28)$ & $(10.95)$ \\
\hline \multirow[t]{2}{*}{ Dual } & $0.00763^{*}$ & $0.00736^{*}$ & $0.00724^{*}$ & 0.116 & 0.0938 & 0.110 \\
\hline & $(1.82)$ & (1.76) & $(1.72)$ & $(1.52)$ & $(1.24)$ & $(1.45)$ \\
\hline \multirow[t]{2}{*}{ First } & 0.00000942 & $0.000359^{* *}$ & $0.000349^{* *}$ & $-0.0203^{* * *}$ & $-0.00864^{* * *}$ & $-0.00942^{* * * *}$ \\
\hline & $(0.07)$ & $(2.41)$ & $(2.32)$ & $(-8.49)$ & $(-3.21)$ & $(-3.48)$ \\
\hline \multirow[t]{2}{*}{ Balance } & 0.000134 & $0.000435^{* * *}$ & $0.000446^{* * *}$ & $-0.0153^{* * *}$ & $-0.00515^{*}$ & $-0.00575^{*}$ \\
\hline & $(0.87)$ & $(2.64)$ & (2.69) & $(-5.53)$ & $(-1.74)$ & $(-1.92)$ \\
\hline \multirow[t]{2}{*}{ Size } & $0.00321^{*}$ & $-0.00396^{*}$ & -0.00353 & $-0.459^{* * *}$ & $-0.690^{* * *}$ & $-0.689^{* * *}$ \\
\hline & (1.77) & $(-1.73)$ & $(-1.53)$ & $(-13.95)$ & $(-16.74)$ & $(-16.54)$ \\
\hline \multirow[t]{2}{*}{ Lev } & $-0.190^{* * *}$ & $-0.186^{* * *}$ & $-0.187^{* * *}$ & $-1.328^{* * *}$ & $-1.207^{* * *}$ & $-1.181^{* * *}$ \\
\hline & $(-24.49)$ & $(-23.97)$ & $(-23.94)$ & $(-9.41)$ & $(-8.62)$ & $(-8.38)$ \\
\hline \multirow[t]{2}{*}{ Growth } & $0.0413^{* * *}$ & $0.0428^{* * *}$ & $0.0424^{* * *}$ & $0.270^{* * * *}$ & $0.323^{* * *}$ & $0.323^{* *}$ \\
\hline & $(13.22)$ & (13.68) & $(13.50)$ & $(4.75)$ & $(5.71)$ & $(5.70)$ \\
\hline \multirow[t]{2}{*}{ Gov $_{t-1}$} & $0.000938^{*}$ & & & $0.0190^{*}$ & & \\
\hline & $(5.59)$ & & & $(6.24)$ & & \\
\hline \multirow[t]{2}{*}{$\mathrm{PEG}_{\mathrm{t}-1}$} & & $5.357^{* *}$ & & & $77.88^{* * * 1}$ & \\
\hline & & (3.44) & & & $(2.77)$ & \\
\hline \multirow[t]{2}{*}{$\mathrm{CAS}_{t-1}$} & & & $-9.69 \mathrm{e}-08$ & & & -0.0000100 \\
\hline & & & $(-0.34)$ & & & $(-1.95)$ \\
\hline \multirow[t]{2}{*}{$\mathrm{C}$} & 0.00537 & $0.144^{* * * *}$ & $0.147^{* * *}$ & $12.26^{* * *}$ & $16.48^{* * *}$ & $16.66^{* * *}$ \\
\hline & $(0.14)$ & $(3.22)$ & $(3.26)$ & $(18.06)$ & $(20.46)$ & (20.46) \\
\hline Adi. $R^{2}$ & 0.1718 & 0.1780 & 0.1771 & 0.1284 & 0.1172 & 0.2995 \\
\hline $\mathrm{F}$ & 3.53 & 3.61 & 3.56 & 6.19 & 5.68 & 5.56 \\
\hline Model & FE & FE & FE & FE & FE & FE \\
\hline Sample Size & 358 & 358 & 358 & 358 & 358 & 358 \\
\hline
\end{tabular}

\subsection{Model estimate result}

By using Stata14.0 the panel data of Chinese listed companies was deal with, the results are shown in Table 1.

Table1. Estimate Results of the Whole Samples.

Note: $*$ indicates significant at the 0.1 level, $* *$ significant at the 0.05 level, $* * *$ significant at the 0.01 level

It can be seen from table 1 that environmental administrative control and market-oriented environmental regulation has a significant positive effect on short- and long-term value. The effect of environmental pollution regulation on 
short- and long-term corporate value is negative. This result account for the fact that punishment of national and local environmental protection department for illegal discharge did not force enterprises to carry out technical innovation to reduce pollution emissions. Overall, environmental regulation tools affect the enterprise value, so the hypothesis 1a was verified. The influence of various environmental regulation tools on short- and long-term value is different. The impact of environmental administrative control and market-oriented environmental regulation on enterprise long-term value were greater than on short-term effects. Although not as hypothesis $1 \mathrm{~b}$ predicted, the model proved that the effect of technology innovation caused by environmental regulation have a cumulative effect and the threshold effect on enterprise value: in the short term, technology innovation is expenditure to enterprises, its short-term impact is not big; In the long run, technological innovation can bring reformation of product and industry structure which infuse new competitive advantage for enterprises. So there is a positive relationship between environmental regulation and the enterprise long-term value. Therefore, hypothesis $1 \mathrm{c}$ was verified.

\subsection{Industry classification regression statistics}

\subsubsection{The model results of environmental regulation and enterprise short-term value}

According to the division in Environmental Information Disclosure Guide of Listed Company (draft) announced by the Ministry of Environmental Protection on September 14, 2010, and Industry Classification Management Catalog of the Environmental Protection Verification of Listed Companies, coal, petrochemical, mining, paper making, fermentation, textile, pharmaceutical, chemical, leather, thermal power, cement, iron and steel, electrolytic aluminum, building materials, metallurgy, brewing 16 sectors were included in heavy pollution industry. The rest were classified as clean production enterprises. Statistical results are as follows:

Table 2. Classified Statistic Results of the Effect of Environmental Regulation on Short-term Value.

\begin{tabular}{|c|c|c|c|c|c|c|}
\hline Variable & \multicolumn{3}{|c|}{ Heavy Pollution Industry } & \multicolumn{3}{|c|}{ Clean Production } \\
\hline \multirow[t]{2}{*}{ Old } & $0.00255^{* * *}$ & $0.00355^{* * *}$ & $0.00311^{* * *}$ & $0.00318^{* * *}$ & $0.00411^{* * *}$ & $0.00358^{* * *}$ \\
\hline & $(3.32)$ & $(5.11)$ & $(4.56)$ & $(4.57)$ & $(6.65)$ & $(5.92)$ \\
\hline \multirow[t]{2}{*}{ Dual } & 0.00678 & 0.00535 & 0.00540 & 0.00511 & 0.00549 & 0.00520 \\
\hline & $(1.09)$ & $(0.86)$ & $(0.86)$ & $(0.95)$ & $(1.03)$ & $(0.98)$ \\
\hline \multirow[t]{2}{*}{ First } & -0.000187 & 0.000169 & 0.000140 & 0.000196 & $0.000609^{* * *}$ & $0.000641^{* * *}$ \\
\hline & $(-1.02)$ & $(0.81)$ & $(0.67)$ & $(1.06)$ & $(2.97)$ & $(3.12)$ \\
\hline \multirow[t]{2}{*}{ Balance } & 0.00000497 & 0.000292 & 0.000292 & 0.000315 & $0.000728^{* * * *}$ & $0.000760^{* * *}$ \\
\hline & $(0.02)$ & $(1.28)$ & $(1.26)$ & $(1.49)$ & $(3.21)$ & $(3.33)$ \\
\hline \multirow[t]{2}{*}{ Size } & $-0.00556^{* *}$ & $-0.0131^{* *}$ & $-0.0125^{* \pi}$ & $0.0126^{2 \pi *}$ & $0.00470^{*}$ & 0.00472 \\
\hline & $(-2.05)$ & $(-3.81)$ & $(-3.60)$ & $(5.51)$ & $(1.65)$ & $(1.65)$ \\
\hline \multirow[t]{2}{*}{ Lev } & -0.198 & $-0.194^{* * * 1+}$ & $-0.195^{* * *}$ & $-0.175^{* * * 1}$ & $-0.169^{*}$ & $-0.171^{* * 7}$ \\
\hline & $(-18.16)$ & $(-17.84)$ & $(-17.75)$ & $(-16.32)$ & $(-15.88)$ & $(-16.03)$ \\
\hline \multirow[t]{2}{*}{ Growth } & $0.0315^{* * *}$ & $0.0329^{* * *}$ & $0.0330^{* * *}$ & $0.0595^{* * *}$ & $0.0611^{* * *}$ & $0.0599^{* * *}$ \\
\hline & $(7.70)$ & $(8.02)$ & $(7.98)$ & $(12.38)$ & $(12.78)$ & $(12.53)$ \\
\hline \multirow[t]{2}{*}{ Gov $_{t-1}$} & $0.000879^{* * *}$ & & & $0.000915^{* * *}$ & & \\
\hline & $(3.56)$ & & & $(4.16)$ & & \\
\hline \multirow[t]{2}{*}{$\mathrm{PEG}_{t-1}$} & & $4.886^{* *}$ & & & $7.749^{* * * *}$ & \\
\hline & & $(2.44)$ & & & $(3.12)$ & \\
\hline \multirow[t]{2}{*}{$\mathrm{CAS}_{t-1}$} & & & -0.000000267 & & & 0.000000135 \\
\hline & & & $(-0.66)$ & & & $(0.36)$ \\
\hline \multirow[t]{2}{*}{$\mathrm{C}$} & $0.214^{* * *}$ & $0.361^{* * *}$ & $0.362^{* *}$ & $-0.215^{* * *}$ & -0.0773 & -0.0635 \\
\hline & $(3.89)$ & $(5.39)$ & $(5.33)$ & $(-4.45)$ & $(-1.37)$ & $(-1.13)$ \\
\hline Adi. $R^{2}$ & 0.1612 & 0.1707 & 0.1700 & 0.2315 & 0.3659 & 0.3710 \\
\hline $\mathrm{F}$ & 3.25 & 3.34 & 3.3 & 4.06 & 4.06 & 4.04 \\
\hline Model & FE & FE & FE & $\mathrm{FE}$ & $\mathrm{FE}$ & FE \\
\hline Sample Size & 202 & 202 & 202 & 156 & & 153 \\
\hline
\end{tabular}

Note: $*$ indicates significant at the 0.1 level, ${ }^{*} *$ significant at the 0.05 level, $* * *$ significant at the 0.01 level

To both clean production enterprises and pollution intensive enterprises, the influence of environmental administrative controls on short- and long-term value, although small, but is all significantly positive. Emission charges as market-oriented environmental regulation promoted enterprise short-term value. The influence of the environmental administrative controls on pollution intensive enterprise is less than on clean production-oriented enterprises. As the same, the influence of emission charges on pollution intensive enterprise is less than on clean production-oriented enterprises. The effects of environmental pollution regulation on short-term value of pollution intensive enterprise is negative, of clean production enterprise is positive. Both for pollution intensive enterprise and clean productionoriented enterprises, the impacts of environmental pollution regulation are small, and not significant. 


\subsubsection{The model estimate results of environmental regulation and enterprise long-term value}

Table 3. Classified Statistic Results of the Effect of Environmental Regulation on Long-term Value.

\begin{tabular}{|c|c|c|c|c|c|c|}
\hline Variable & \multicolumn{3}{|c|}{ Heavy Pollution Industry } & \multicolumn{3}{|c|}{ Clean Production } \\
\hline \multirow[t]{2}{*}{ Old } & $0.0874^{* * *}$ & $0.101^{* \text { ** }}$ & $0.0955^{* * *}$ & $0.0824^{* * * *}$ & $0.0899^{* * * *}$ & $0.0856^{* * *}$ \\
\hline & $(6.85)$ & $(8.77)$ & $(8.47)$ & $(5.59)$ & $(6.87)$ & $(6.61)$ \\
\hline \multirow[t]{2}{*}{ Dual } & $0.204^{*}$ & 0.149 & 0.161 & 0.0143 & 0.0153 & 0.0347 \\
\hline & $(1.96)$ & $(1.45)$ & $(1.56)$ & $(0.13)$ & $(0.14)$ & $(0.31)$ \\
\hline \multirow[t]{2}{*}{ First } & $-0.0207^{* * *}$ & $-0.00889^{* *}$ & $-0.00985^{* * *}$ & $-0.0210^{* * *}$ & $-0.00975^{* *}$ & $-0.0105^{* *}$ \\
\hline & $(-6.75)$ & $(-2.56)$ & $(-2.84)$ & $(-5.36)$ & $(-2.25)$ & $(-2.38)$ \\
\hline \multirow[t]{2}{*}{ Balance } & $-0.0171^{* * *}$ & $-0.00714^{*}$ & $-0.00759^{* *}$ & $-0.0136^{* * *}$ & -0.00294 & -0.00369 \\
\hline & $(-4.82)$ & $(-1.88)$ & $(-1.99)$ & $(-3.02)$ & $(-0.61)$ & $(-0.76)$ \\
\hline \multirow[t]{2}{*}{ Size } & $-0.446^{* * *}$ & $-0.694^{* * *}$ & $-0.686^{* * *}$ & $-0.475^{* * *}$ & $-0.678^{* * *}$ & $-0.684^{* * *}$ \\
\hline & $(-9.84)$ & $(-12.16)$ & $(-11.95)$ & $(-9.81)$ & $(-11.21)$ & $(-11.17)$ \\
\hline \multirow[t]{2}{*}{ Lev } & $-1.736^{* * *}$ & $-1.620^{* * *}$ & $-1.603^{* * *}$ & $-0.686^{* * *}$ & $-0.561^{* *}$ & $-0.535^{* *}$ \\
\hline & $(-9.54)$ & $(-8.97)$ & $(-8.84)$ & $(-3.02)$ & $(-2.49)$ & $(-2.35)$ \\
\hline \multirow[t]{2}{*}{ Growth } & $0.162^{* *}$ & $0.217^{* * *}$ & $0.217^{* * *}$ & $0.468^{* * *}$ & $0.508^{* * *}$ & $0.508^{* * *}$ \\
\hline & $(2.37)$ & $(3.18)$ & $(3.18)$ & $(4.59)$ & $(5.01)$ & $(4.97)$ \\
\hline \multirow[t]{2}{*}{ Gov $_{t-1}$} & $0.0211^{* * *}$ & & & $0.0161^{\text {*** }}$ & & \\
\hline & $(5.11)$ & & & $(3.45)$ & & \\
\hline \multirow[t]{2}{*}{$P E G_{t-1}$} & & $72.58^{* *}$ & & & $103.8^{* *}$ & \\
\hline & & $(2.19)$ & & & $(1.97)$ & \\
\hline \multirow[t]{2}{*}{$\mathrm{CAS}_{t-1}$} & & & -0.00000822 & & & -0.0000119 \\
\hline & & & $(-1.23)$ & & & $(-1.48)$ \\
\hline \multirow{2}{*}{$\mathrm{C}$} & $12.09^{* * *}$ & $16.80^{* * * *}$ & $16.85^{* *}$ & $12.42^{* *}$ & $15.88^{* * *}$ & $16.27^{* * * 4}$ \\
\hline & $(13.14)$ & $(15.12)$ & $(15.01)$ & $(12.14)$ & (13.32) & $(13.55)$ \\
\hline Adi. $R^{2}$ & 0.1519 & 0.3620 & 0.3640 & 0.0857 & 0.2175 & 0.2120 \\
\hline $\mathrm{F}$ & 6.05 & 5.60 & 5.51 & 6.26 & 5.65 & 5.51 \\
\hline Model & $\mathrm{FE}$ & $\mathrm{FE}$ & FE & $\mathrm{FE}$ & $\mathrm{FE}$ & $\mathrm{FE}$ \\
\hline Sample Size & 202 & 202 & 202 & 156 & & 153 \\
\hline
\end{tabular}

Note: $*$ indicates significant at the 0.1 level, $* *$ significant at the 0.05 level, $* * *$ significant at the 0.01 level

It can be seen from the chart that to all enterprises the environment administrative controls have significantly positive on long-term. Promoting effect of emission charges on long-term value of enterprises is most obvious. Environmental pollution regulation has negative effects on two types of companies, although numeric is small and not significant, but it is enough to declare the current environmental administrative penalty does not play the role of negative reinforcement to force enterprises to implement innovation.

\section{Policy enlightenment}

The government should implement targeted environmental regulation measures based on industry classification. For pollution intensive enterprises, through rules and regulations, illegal punishment, emission charges, new energy and new material subsidies and other measures not only lead them to speed up the process of shifting from end-of-pipe treatment to clean production, but also get revenue from the process, so that to encourage enterprises to respond to the government gradually stricter and sophisticated environmental protection policy actively. For clean production-oriented enterprises, it is reasonable to improve the industry standard and strength of environmental regulation to push production process optimization through the government's external constraint, but at the same time pay attention not to only improve environmental regulation standards, be careful that too much environmental regulation may beyond the withstand scope of enterprises.

\section{Acknowledgement}

A Project Funded by the Priority Academic Program Development of Jiangsu Higher Education Institutions and National Natural Science Foundation of China(Grant No. 71472090)

\section{References}

1. Ling Li, Feng Tao. Selection of Optimal Environmental Regulation Intensity for Chinese Manufacturing Industry. China Industrial Economics,2012,5:70-82.

2. Qian Zhang. Impact of Market based Incentive Environmental Regulations on Different Types of Technology Innovation and Regional Heterogeneity.Forward Position or Economics,2015,3(2):36-48. 
3. Shu Li, WeiGuo Weng. Local environmental regulation and total factor productivity growth in China. Journal of Financial Research, 2014, 40 (2) : $19-29$. 